\title{
Resistance to fire of walls constituted by hollow blocks: Experiments and thermal modeling
}

\author{
F. Al Nahhas ${ }^{\text {a }}$, R. Ami Saada ${ }^{a, *}$, G. Bonnet ${ }^{a}$, P. Delmotte ${ }^{b}$ \\ ${ }^{a}$ LaM, Laboratoire de Mécanique, Université de Marne-La-Vallée, 5 Bd Descartes, Cité Descartes, 77454 Marne-La-Vallée Cedex 2, France \\ ${ }^{\mathrm{b}}$ Centre Scientifique et Technique du Bâtiment, BP 2, F-77421 Marne-La-Vallée Cedex 2, France \\ Abstract
}

The thermo-mechanical behavior of masonry walls is investigated from both experimental and theoretical points of view. Fire tests have been performed in order to evaluate the thermo-mechanical resistance of masonry wall submitted to a vertical load (13 ton/m) and exposed to temperatures ranging from 20 to $1200{ }^{\circ} \mathrm{C}$. As a result we measure the temperature evolution inside the wall and evaluate the vertical and lateral displacements of this wall during heating for a period of $6 \mathrm{~h}$. These results are affected significantly by phase-change phenomena which appeared as a plateau around ${ }^{\circ} \mathrm{C}$ in temperature-time curves. A theoretical model was then developed to describe the experimental results taking in to account convection, conduction and radiation phenomena inside the wall. In addition, liquid water migration using an enthalpic method is considered.

Keywords: Wall heat conduction; Phase-change phenomenon; Firewall tests; Fire resistant masonry; Wall heat convection; Wall heat radiation

\section{Introduction}

Recently the development of construction materials for bearing walls in buildings has made remarkable progress. The use of masonry walls seems to have many benefits $[1,3,6-9,12]$, the first of which is the fact that a single element can fulfil several functions including structure, fire protection, thermal and sound insulation, weather protection and sub-division of space. The second major advantage is related to the durability of materials which may remain in service for many years. From an architectural point of view, masonry offers advantages in terms of great flexibility of plan form. The advantages of masonry wall construction are therefore considerable, but, as with all materials, they must be able to withstand fire. The resistance to fire of masonry wall $[11,13-16]$ includes not only the capacity of constitutive blocks alone, but also the one

\footnotetext{
* Corresponding author. Tel.: +331609577 80; fax: +33160957799. E-mail address: amisaada@univ-mlv.fr (R. Ami Saada).
}

of its main constituent materials i.e. aggregate, cement and water. The contribution of the aggregates and cement to fire resistance of structure were discussed earlier [18]. Although there is much research concerning the effect of cement and aggregate on the resistance to fire of masonry walls, there is a need to pay attention to the role of the water content $[5,17]$. The present work is devoted to the study of this effect on the thermal response of masonry walls subjected to fire. This paper is in two parts:

- The experimental part, which is principally devoted to the temperature and displacement measurement within the masonry wall exposed to temperatures ranging from 20 to $1200^{\circ} \mathrm{C}[2]$.

- The theoretical study, which establishes a thermal model taking into account heat transfer through the wall by convection, radiation and conduction.

This model also accounts for the liquid water migration inside the wall using an enthalpic method: specific heat variation in a small interval of temperature around the 


\begin{tabular}{|c|c|c|c|}
\hline \multicolumn{4}{|c|}{ Nomenclature } \\
\hline$c$ & specific heat $(\mathrm{J} /(\mathrm{kg} \mathrm{K}))$ & $T$ & temperature $\left({ }^{\circ} \mathrm{C}\right)$ \\
\hline$c_{\mathrm{eq}}$ & equivalent specific heat $(\mathrm{J} /(\mathrm{kg} \mathrm{K}))$ & $T_{0}$ & initial temperature $\left({ }^{\circ} \mathrm{C}\right)$ \\
\hline$e$ & thickness of the partition $(\mathrm{m})$ & $T_{\text {furnace }}$ & temperature of the furnace $\left({ }^{\circ} \mathrm{C}\right)$ \\
\hline$e_{i}$ & thickness of the sub-partition $i(i=1,2,3)(\mathrm{m})$ & $T_{\text {iso }}$ & normalized temperature-curve $\left({ }^{\circ} \mathrm{C}\right)$ \\
\hline$E_{v}$ & energy absorbed $(\mathrm{J})$ & $\delta T$ & interval of temperature $\left({ }^{\circ} \mathrm{C}\right)$ \\
\hline$h_{i}$ & convection coefficient $(i=1,2.3,4)\left(\mathrm{W} /\left(\mathrm{m}^{2} \mathrm{~K}\right)\right.$ & $w$ & water content \\
\hline K & intrinsic permeability $\left(\mathrm{m}^{2}\right)$ & $\alpha_{i}(x)$ & the interpolation function \\
\hline$L$ & latent heat of water vaporisation $(\mathrm{J} / \mathrm{kg})$ & $\phi$ & porosity \\
\hline$m_{1}$ & mass of liquid water $(\mathrm{kg})$ & $\lambda$ & thermal conductivity $\left(\mathrm{W} /\left(\mathrm{m}{ }^{\circ} \mathrm{C}\right)\right)$ \\
\hline & radiation heat flow $\left(\mathrm{W} / \mathrm{m}^{2}\right)$ & $\rho$ & mass density $\left(\mathrm{kg} / \mathrm{m}^{3}\right)$ \\
\hline$q_{\text {conv }}$ & convection heat flow $\left(\mathrm{W} / \mathrm{m}^{2}\right)$ & $\rho_{\mathrm{d}}$ & mass density at dry state $\left(\mathrm{kg} / \mathrm{m}^{3}\right)$ \\
\hline$q_{\text {cond }}$ & conduction heat flow $\left(\mathrm{W} / \mathrm{m}^{2}\right)$ & $\varepsilon_{\mathrm{i}}$ & emissivity coefficient $(i=1,2,3)$ \\
\hline$S_{0}$ & equivalent area heat $\left(\mathrm{J} / \mathrm{m}^{2} \mathrm{~K}\right)$ & $\sigma$ & Stephan Boltzman constant $\left(\sigma=5.67 \times 10^{-8}\right)$ \\
\hline$t$ & time $(\min )$ & & \\
\hline
\end{tabular}

temperature of ebullition $\left(100^{\circ} \mathrm{C}\right)$ for modeling the water evaporation.

\section{Experimental tests}

\subsection{Introduction}

This Section presents the experimental results including the temperature and the displacements of a masonry wall subjected to high temperatures. These results are discussed to obtain qualitative information on the thermo-mechanical behavior of the wall, in particular the phase-change effect. Moreover, it will form the basis for a quantitative interpretation of the global thermal model developed in Sections 3 and 4 .

\subsection{Materials}

\subsubsection{Blocks}

The form of blocks used to construct the wall is presented in Fig. 1. The apparent compressive strength of the block is $4 \mathrm{MPa}$. It is obtained by compacting the aggregates with mortar using a particular mold to produce the hollow blocks. The measured porosity and intrinsic permeability are equal to $\phi=21 \%$ and $K=2 \times 10^{12} \mathrm{~m}^{2}$, respectively. This type of block is widely used in the majority of building construction in France.

\subsubsection{Wall geometry and boundary conditions}

The geometry of the wall used is presented in Fig. 2, where the vertical and horizontal sections are presented also. This wall is constructed by assembling the hollow blocks described above.

The horizontal and vertical joints are filled by a mortar which has the same mechanical characteristics as the blocks. The top and bottom edges of the wall are filled by a mortar of thickness equal to $30 \mathrm{~mm}$ and $20 \mathrm{~mm}$, respectively.

\subsection{Furnace and mechanical apparatus}

A vertical furnace with dimensions of $(3 \times 3 \times 1.4 \mathrm{~m})$ is used. It has $12 \times 224 \mathrm{~kW}$ gas-fired burners. The temperature evolution inside the furnace is controlled by the thermocouple type $\mathrm{K}$ and follows the normalized temperature-curve (ISO) [2], given by Eq. (1):

$T_{\text {furnace }}=T_{\text {iso }}=T_{0}+345 \log _{10}(8 t+1)$

where $T_{0}$ is the initial temperature, $t$ the time in minutes. The maximal temperature which can be measured by the thermocouples is $1250{ }^{\circ} \mathrm{C}$ with an accuracy of $\pm 10^{\circ} \mathrm{C}$.

In the normalized temperature-curve (ISO) [2], the temperature reaches $900{ }^{\circ} \mathrm{C}$ at $40 \mathrm{~min}$ and reaches $1200{ }^{\circ} \mathrm{C}$ at $6 \mathrm{~h}$.

A uniform vertical load $(357 \mathrm{kN})$ is applied on the wall using the mechanical apparatus presented in Fig. 3. It is composed principally of a portal frame metallic beam and two jacks (V1 and V2) which apply the vertical load on the wall by means of a metallic frame. It is servo-controlled by a servo-mechanism which commands an autonomous hydraulic plant. The capacity of each jack is $\pm 500 \mathrm{kN}$ and the force applied can be controlled with an accuracy of $\pm 2 \mathrm{kN}$. The vertical space between this frame and lateral parts of the wall is filled with a rock wool.

\subsection{Temperature measurement}

The temperature evolution inside the wall is measured using thermocouples fixed inside three blocks (see Fig. 4a). The position of thermocouples in each block is indicated in Fig. 4b. The position of the blocks is chosen according to the French regulation (CSTB) [2].

\subsection{Displacement measurement}

The vertical and horizontal displacements were measured using the LVDT transducers, which have a measurement 


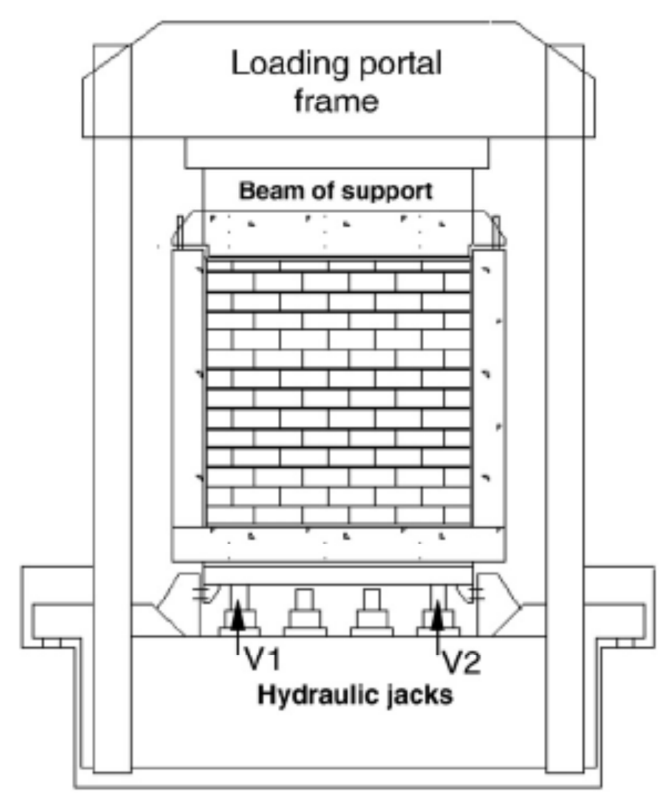

Fig. 3. Mechanical testing apparatus.

ear part ranging from 0 to $25 \mathrm{~min}$, followed by the second part where the displacement is quasi-constant until $45 \mathrm{~min}$.

We remark that the displacements of points $(2,4$ and 6$)$ situated in the median axis of the wall is more important than those corresponding to the points ( 3 and 7 ) which are near the bottom edge of wall. These last measurements are near the rigid metallic frame.

2.6.2.2. Vertical displacement. The average vertical displacement measured by the two LVDT transducers is reported in Fig. 8. We can point out a linear part of dis- placement between 0 and $30 \mathrm{~min}$ followed by a plateau until $90 \mathrm{~min}$. Then the displacement is increasing. The plateau observed from 30 to $90 \mathrm{~min}$ can be related to the same features as the one on temperature-time curves (see the curve corresponding to point 4 in Fig. 6) which can be interpreted as follows: thermal expansion of the constitutive material creates vertical and lateral deformations of the wall. These deformations take a constant value when the temperature of a great part of the wall becomes constant during the evaporation of liquid water inside the material.

\section{Thermal modeling}

The thermal transfer across different parts of the wall is studied using a simplified one-dimensional model which takes into account: convection, radiation and conduction. The energy absorbed to evaporate the interstitial water is also taken into account in this model. The model is based on a finite difference scheme, each partition of the wall being divided into three sub-partitions.

\subsection{Energy equation}

The method to construct the system of equations is to apply the energy balance to each sub-partition of the wall. The temperature is assumed to vary quadratically within each partition (Fig. 9). An interpolation function within each partition describes the temperature variation from the temperature of three nodes ((1), (2) and (3) (see Fig. 9) for a partition 1, for example). The general form of the energy balance for each sub-partition $i$ can be written as follows [4]:

$e_{i} \cdot \rho \cdot c \cdot \frac{\mathrm{d} T}{\mathrm{~d} t}=q_{\mathrm{ra}}+q_{\mathrm{conv}}+q_{\mathrm{cond}}-L \frac{\mathrm{d} E_{\mathrm{v}}}{\mathrm{d} t}$

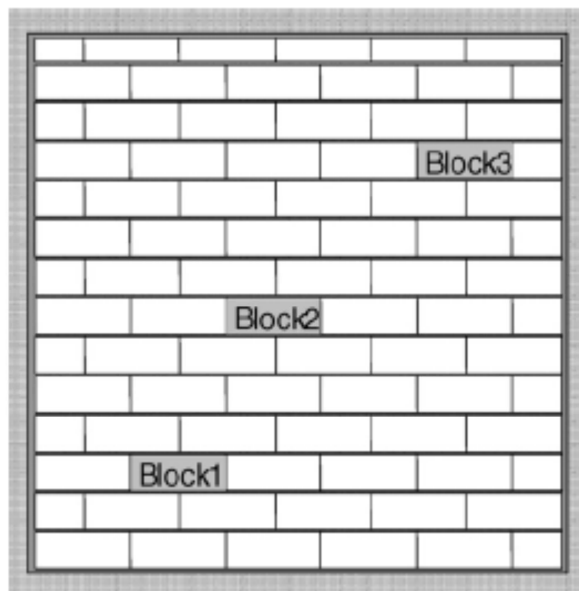

(a)

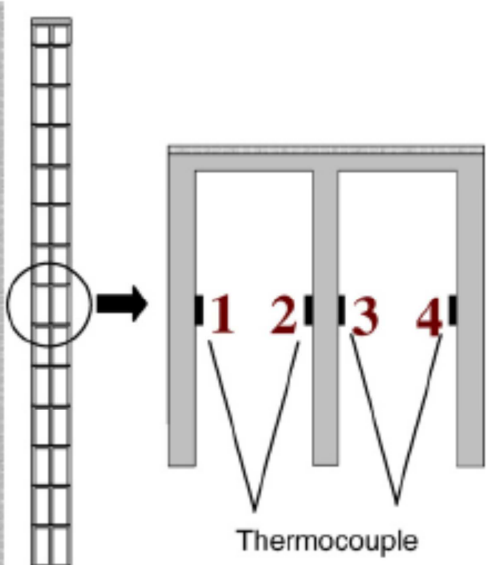

(b)

Fig. 4. Position of thermocouples in each block in the wall. 


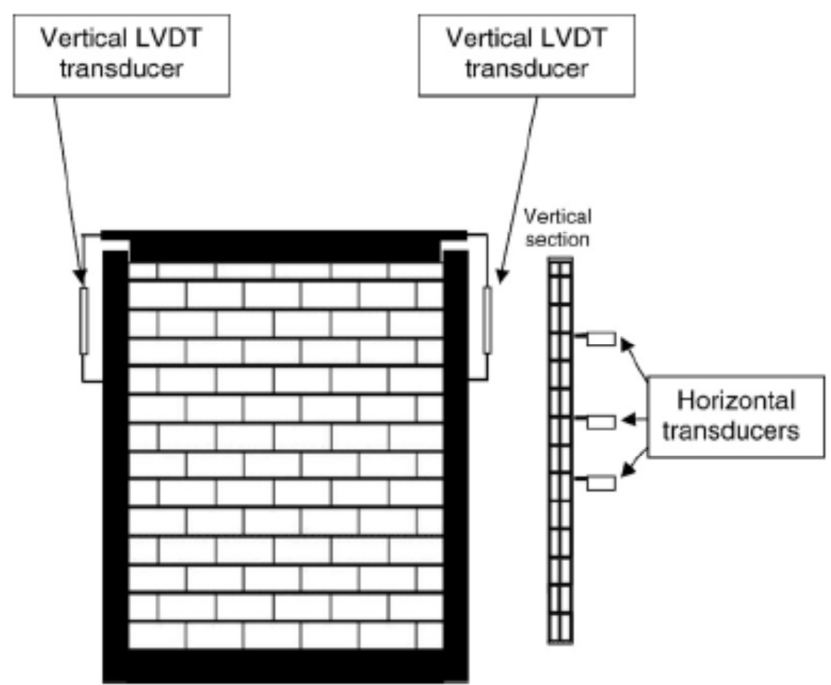

Fig. 5. Horizontal and vertical displacements measurement.

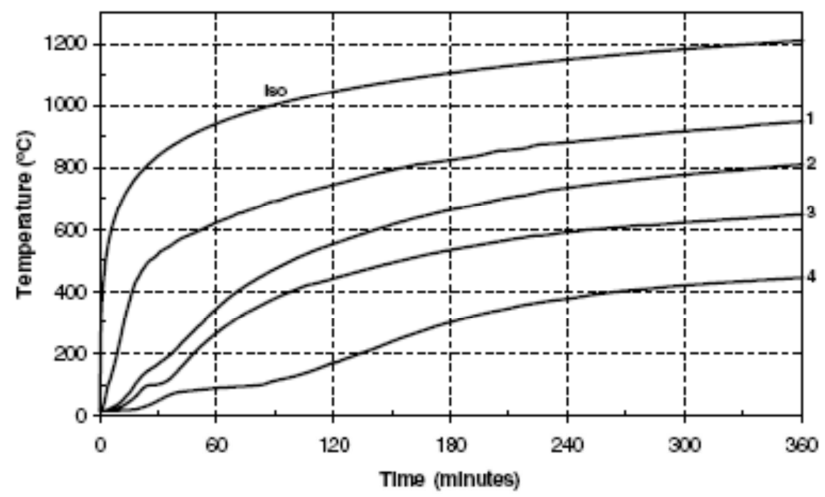

Fig. 6. Temperature evolution as function of time measured at several points as defined in Fig. 4.
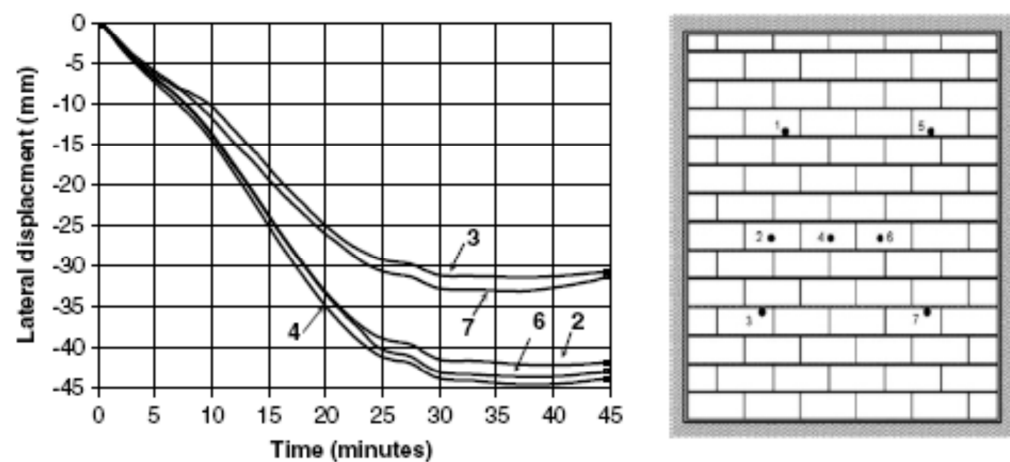

Fig. 7. Result of lateral displacement measurement in several points of the wall (1-7) obtained using horizontal transducers as defined in Fig. 5. 


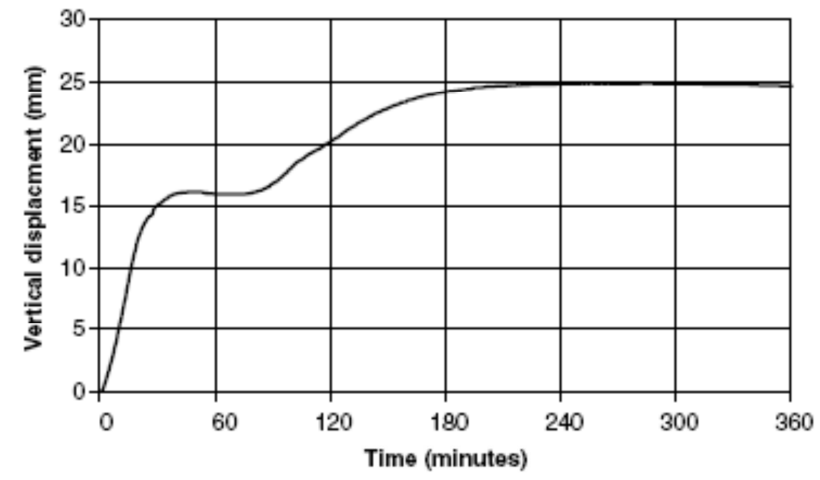

Fig. 8. Result of vertical displacement measurement obtained by vertical transducers as defined in Fig. 5 .

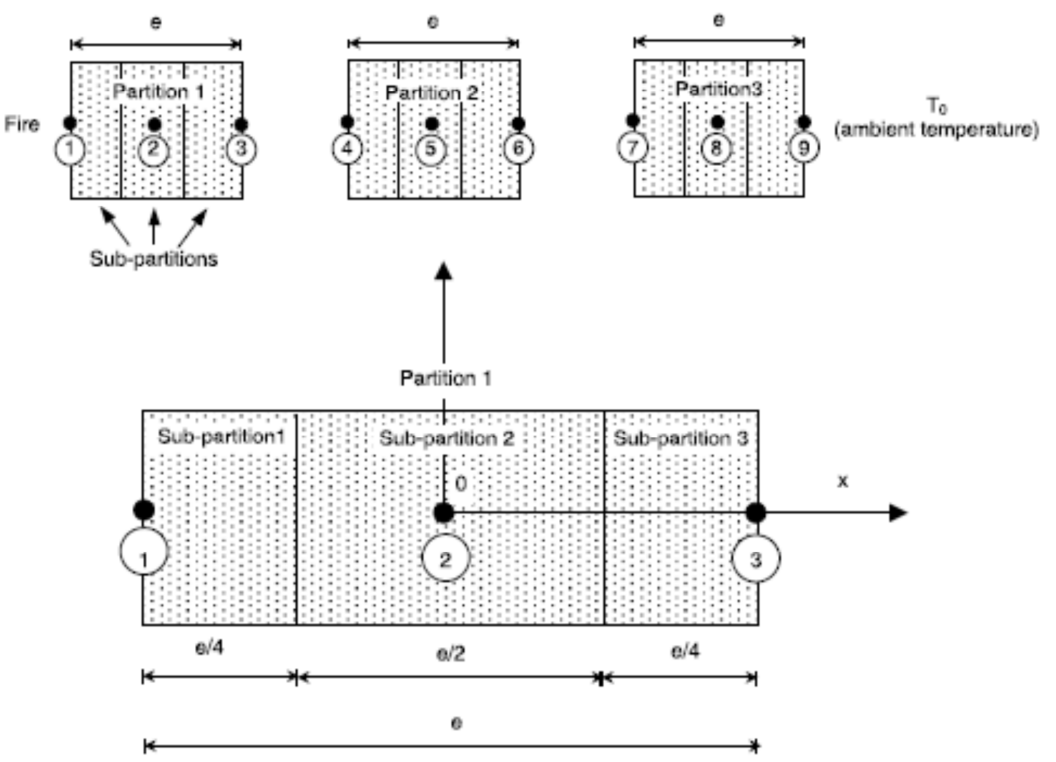

Fig. 9. Definition of partitions and sub-partitions of the wall.

where $e_{i}$ is the thickness of sub-partition $i, \rho$ the density, $c$ a specific heat of the constitutive material. $q_{\mathrm{ra}}$ : radiation heat flow, $q_{\text {conv }}$ : convection heat flow, $q_{\text {cond: }}$ conduction heat flow and $E_{\mathrm{v}}$ is the energy absorbed to evaporate the interstitial water. In order to simplify the model, the phasechange phenomenon (physically occuring at exactly $100^{\circ} \mathrm{C}$ under atmospheric pressure) is simulated by a continuous phenomenon during a temperature interval of $\delta T$ around $100^{\circ} \mathrm{C}$. With this assumption, the energy absorbed during the evaporation can be written:

$E_{\mathrm{v}}=\int_{100-\delta T}^{100+\delta T} L \frac{\mathrm{d}_{m_{m}}}{\mathrm{~d} t} \int_{100-\delta T}^{100+\delta T} S_{0} \frac{\mathrm{d} T}{\mathrm{~d} t} \mathrm{~d} t$

where $L$ is the latent heat of water vaporization, $m_{1}$ : mass of liquid water by unit of volume $\left(m_{1}=w \cdot e_{i} \cdot \rho\right), w$ is the water content and $S_{0}$ is the heat absorbed by evaporation for an increasing of temperature of $1{ }^{\circ} \mathrm{C}$, given by:

$S_{0}=\frac{L \cdot w \cdot e_{i} \cdot \rho}{2 \cdot \delta T}$

The computation were made with $\delta T=5^{\circ} \mathrm{C}$.

From Eq. (3) we can write:

$\frac{\mathrm{d}_{E_{\mathrm{v}}}}{\mathrm{d} t}=S_{0} \frac{\mathrm{d} T}{\mathrm{~d} t}$

Introducing Eq. (5) into Eq. (2) leads to:

$e_{i} \cdot \rho \cdot\left[c+c_{\mathrm{eq}}\right] \frac{\mathrm{d} T}{\mathrm{~d} t}=q_{\mathrm{ra}}+q_{\mathrm{cunv}}+q_{\mathrm{cond}}$

where : $c_{\text {eq }}=\frac{S_{0}}{e_{i} \cdot \rho}$ 
Combining Eqs. (4) and (7) allows to calculate $c_{\text {eq. }}$. It can be written:

$$
c_{\mathrm{eq}}=\frac{L \cdot w}{2 \cdot \delta T}
$$

Finally the energy balance for each sub-partition $i$ can be written under the following global form:

$e_{i} \cdot \rho \cdot c_{i} \frac{\mathrm{d} T}{\mathrm{~d} t}=q_{\mathrm{ra}}+q_{\mathrm{couv}}+q_{\mathrm{arnd}}$

where $c_{i}=c+c_{\text {eq }}$.

\subsubsection{Energy balance for the first partition}

Fig. 9 represent the first partition of the wall with a thickness equal to $e$. The thickness of central sub-partition is equal to $(e / 2)$, the other sub-partitions have a thickness equal to $(e / 4)$. At each sub-partition is attributed one node and the first partition can be therefore represented by three nodes (see Fig. 9).

The distribution of temperature in each partition is supposed to have a parabolic form as follows:

$T(x)=\alpha_{1}(x) T_{1}+\alpha_{2}(x) T_{2}+\alpha_{3}(x) T_{3}$

The temporal derivative of Eq. (10) can be written:

$\dot{T}(x)=\alpha_{1}(x) \dot{T}_{1}+\alpha_{2}(x) \dot{T}_{2}+\alpha_{3}(x) \dot{T}_{3}$

where $T_{1}, T_{2}, T_{3}$ are the nodal temperatures in points 1,2 and 3, respectively and $\alpha_{1}(x), \alpha_{2}(x)$ and $\alpha_{3}(x)$ are the interpolation functions which are given by:

$\alpha_{1}(x)=x\left(x-\frac{e}{2}\right) \times \frac{2}{e^{2}}$,

$\alpha_{2}(x)=\left(x-\frac{e}{2}\right)\left(x+\frac{e}{2}\right) \times\left(-\frac{4}{e^{2}}\right)$,

$\alpha_{3}(x)=x\left(x+\frac{e}{2}\right) \times \frac{2}{e^{2}}$

3.1.1.1. Energy balance for the sub-partition (1). The energy balance of the sub-partition (1) can be written:

$\int_{-\epsilon / 2}^{-\epsilon / 4}\left(\rho \cdot c_{1} \cdot \dot{T}\right) \mathrm{d} x=q_{(\text {firrece- }-1)}+\left.\lambda \frac{\partial T}{\partial x}\right|_{x=\left(-\frac{s}{4}\right)}$

Using Eq. (11) allows one to write the left term of Eq. (13) as follows:

$\int_{-\varepsilon / 2}^{-\epsilon / 4}\left(\rho \cdot c_{1} \cdot \dot{T}\right) \mathrm{d} x=\rho \cdot c_{1} \cdot\left(\dot{T}_{1} \cdot a_{11}+\dot{T}_{2} \cdot a_{12}+\dot{T}_{3} \cdot a_{13}\right)$

where $a_{11}=\frac{e}{6}, a_{12}=\frac{5}{48} e$ and $a_{13}=-\frac{1}{48} e$. The other terms of Eq. (13) are defined:

$q_{\mathrm{ra}}=\varepsilon_{1} \sigma\left(T_{\text {fumase }}^{4}-T_{1}^{4}\right)$

where $\varepsilon_{1}$ is the emissivity coefficient between the furnace and the node (1), $\sigma$ is the Stephan Boltzman constant $\left(\sigma=5.67 \times 10^{-8}\right), T_{\text {furnace }}$ and $T_{1}$ are the temperature of the furnace and at node (1), respectively.

$q_{\mathrm{conv}}=h_{1}\left(T_{\text {fumace }}-T_{1}\right)$ where $h_{1}$ is the convection coefficient between the furnace and the node (1).

$\left.\frac{\partial T}{\partial x}\right|_{\frac{e}{4}}=T_{1} c_{11}+T_{2} c_{12}+T_{3} c_{13}$

where $c_{11}=\left.\frac{\partial x_{1}}{\partial x}\right|_{x=-\frac{e}{q}}, c_{12}=\left.\frac{\partial x_{2}}{\partial x}\right|_{x=-\frac{e}{2}}$ and $c_{13}=\left.\frac{\partial \alpha_{1}}{\partial x}\right|_{x=-\frac{\xi}{q}}$

The final form of the energy balance for the sub-partition (1) can be then written:

$$
\begin{aligned}
\dot{T}_{1} \cdot & a_{11}+\dot{T}_{2} \cdot a_{12}+\dot{T}_{3} \cdot a_{13} \\
= & \frac{1}{\rho \cdot c_{1}}\left[h_{1}\left(T_{\text {fumzes }}-T_{1}\right)+\sigma\left(T_{\text {firmece }}^{4}-T_{1}^{4}\right)\right. \\
& \left.+\lambda\left(T_{1} c_{11}+T_{2} c_{12}+T_{3} c_{13}\right)\right]
\end{aligned}
$$

where $\lambda$ is the conduction coefficient.

3.1.1.2. Energy balance for the sub-partition (2). The energy balance for the sub-partition (2) can be written:

$\int_{-\epsilon / 4}^{\epsilon / 4}\left(\rho \cdot c_{2} \cdot \dot{T}\right) \mathrm{d} x=-\left.\lambda \frac{\partial T}{\partial x}\right|_{x=\left(-\frac{\varepsilon}{4}\right)}+\left.\lambda \frac{\partial T}{\partial x}\right|_{x=\left(\frac{s}{4}\right)}$

Similarly to the development done for sub-partition (1) Eq. (19) becomes:

$$
\begin{aligned}
\dot{T}_{1} \cdot & a_{21}+\dot{T}_{2} \cdot a_{22}+\dot{T}_{3} \cdot a_{23} \\
= & \frac{1}{\rho \cdot c_{2}}\left[-\lambda\left(T_{1} c_{11}+T_{2} c_{12}+T_{3} c_{13}\right)\right. \\
& \left.+\lambda\left(T_{1} c_{21}+T_{2} c_{22}+T_{3} c_{23}\right)\right]
\end{aligned}
$$

where $a_{21}=\frac{1}{48} e, a_{22}=\frac{11}{24} e, a_{23}=\frac{1}{48} e$.

3.1.1.3. Energy balance for sub-partition (3). The energy balance of this sub-partition can be written:

$\int_{e / 4}^{\epsilon / 2}(\rho \cdot c \cdot \dot{T}) \mathrm{d} x=q_{\mathrm{rz}}+q_{\mathrm{auv}}+\left.\lambda \frac{\partial T}{\partial x}\right|_{x=\left(\frac{\rho}{4}\right)}$

where $q_{\mathrm{rz}}=\varepsilon_{2} \sigma\left(T_{3}^{4}-T_{4}^{4}\right) \quad$ and $\quad q_{\mathrm{arv}}=-h_{2}\left(T_{3}-T_{4}\right)$

with $\varepsilon_{2}$ and $h_{2}$ are the emissivity and convection coefficients, respectively, and $T_{4}$ is the temperature on point (4) defined in Fig. 9. Similarly to the development done for the sub-partitions (1) and (2), the energy balance for the sub-partition (3) can be written as follows:

$$
\begin{aligned}
\dot{T}_{1} \cdot & a_{31}+\dot{T}_{2} \cdot a_{32}+\dot{T}_{3} \cdot a_{33} \\
= & \frac{1}{\rho \cdot c_{3}}\left[-h_{2}\left(T_{3}-T_{4}\right)-\sigma\left(T_{3}^{4}-T_{4}^{4}\right)\right. \\
& \left.-\lambda\left(T_{1} c_{21}+T_{2} c_{22}+T_{3} c_{23}\right)\right]
\end{aligned}
$$

where $a_{31}=-\frac{1}{48} e, a_{32}=\frac{5}{48} e, a_{33}=\frac{1}{6} e$.

Finally the energy balance for partition (1) can be written under the matrix form below:

$$
\left[\begin{array}{lll}
a_{11} & a_{12} & a_{13} \\
a_{21} & a_{22} & a_{23} \\
a_{31} & a_{32} & a_{33}
\end{array}\right] \times\left[\begin{array}{l}
\dot{T}_{1} \\
\dot{T}_{2} \\
\dot{T}_{3}
\end{array}\right]=\left[\begin{array}{l}
b_{1} \\
b_{2} \\
b_{3}
\end{array}\right]
$$


where

$$
\left[a_{i j}\right]=\left[\begin{array}{ccc}
1 / 6 & 5 / 48 & -1 / 48 \\
1 / 48 & 11 / 24 & 1 / 48 \\
-1 / 48 & 5 / 48 & 1 / 6
\end{array}\right] \times e
$$

and

$b_{1}=\frac{h_{1}\left(T_{\text {furnace }}-T_{1}\right)+\sigma\left(T_{\text {furnax }}^{4}-T_{1}^{4}\right)+\lambda\left(T_{1} c_{11}+T_{2} c_{12}+T_{3} c_{13}\right)}{\rho \cdot c_{1}}$

$b_{2}=\frac{\lambda\left(T_{1} c_{21}+T_{2} c_{22}+T_{3} c_{23}\right)-\lambda\left(T_{1} c_{11}+T_{2} c_{12}+T_{3} c_{13}\right)}{\rho \cdot c_{2}}$

$b_{3}=\frac{-h_{2}\left(T_{3}-T_{4}\right)-\sigma\left(T_{3}^{4}-T_{4}^{4}\right)-\lambda\left(T_{1} c_{21}+T_{2} c_{22}+T_{3} c_{23}\right)}{\rho \cdot c_{3}}$

or

$$
\left[\begin{array}{l}
\dot{T}_{1} \\
\dot{T}_{2} \\
\dot{T}_{3}
\end{array}\right]=\left[a_{i j}\right]^{-1}\left[\begin{array}{l}
b_{1} \\
b_{2} \\
b_{3}
\end{array}\right]
$$

The development of calculation of the energy balance for the second Section A.1 and third Section A.2 partitions is given in the appendix.

\subsection{Coupled model equations}

The resulting Eqs. (24), (26) and (28) (given in the appendix) can be written under the following matrix form:

$$
\begin{aligned}
& {\left[\begin{array}{lllllllll}
\dot{T}_{1} & \dot{T}_{2} & \dot{T}_{3} & \dot{T}_{4} & \dot{T}_{5} & \dot{T}_{6} & \dot{T}_{7} & \dot{T}_{8} & \dot{T}_{9}
\end{array}\right]^{\mathrm{T}}} \\
& =\left[\begin{array}{ccc}
{\left[a_{i j}\right]^{-1}} & 0 & 0 \\
0 & {\left[a_{i j}\right]^{-1}} & 0 \\
0 & 0 & {\left[a_{i j}\right]^{-1}}
\end{array}\right] \\
& \times\left[\begin{array}{lllllllll}
b_{1} & b_{2} & b_{3} & b_{4} & b_{5} & b_{6} & b_{7} & b_{8} & b_{9}
\end{array}\right]^{\mathrm{T}}
\end{aligned}
$$

\section{Results and discussion}

The physical parameters of the material used in the thermal model are reported in Table 1. The equivalent specific heat given by Eq. (8) has the value of $C_{\mathrm{eq}}=4954\left(\mathrm{~J} / \mathrm{kg}{ }^{\circ} \mathrm{C}\right)$. The convection and emissivity coefficien ts corresponding to

Table 1

Values of different physical parameters used within the model

\begin{tabular}{lll}
\hline Given parameter & Value & Unit \\
\hline Thickness of the wall & 0.017 & $\mathrm{~m}$ \\
$\begin{array}{l}\text { Mass density of the material at } \\
\text { dry state } \rho_{\mathrm{d}}\end{array}$ & 2000 & $\mathrm{~kg} / \mathrm{m}^{3}$ \\
$\begin{array}{l}\text { Latent heat of water vaporisation } L \\
\text { Radiation coefficient } \sigma\end{array}$ & $2.477 \times 10^{6}$ & $\mathrm{~J} / \mathrm{kg}$ \\
$\begin{array}{l}\text { Initial water content in the partitions } w \\
\text { Specific heat of solid phase } C\end{array}$ & $5.67 \times 10^{-8}$ & - \\
$\begin{array}{l}\text { Initial temperature } T_{0} \\
\text { Thermal conductivity of the material } \lambda\end{array}$ & 900 & - \\
$\begin{array}{l}\text { Interval of temperature of phase } \\
\text { change phenomenon }\end{array}$ & $\begin{array}{l}\mathrm{J} /(\mathrm{kg} \mathrm{K}) \\
\text { (100-5, 100 }\end{array}$ & ${ }^{\circ} \mathrm{C}$ \\
\hline
\end{tabular}

Table 2

Values of convection and emissivity coefficients in each partition, used within the model

\begin{tabular}{llll}
\hline Given parameter & & Value & Unit \\
\hline Convection coefficients of different partitions & $h_{1}$ & 20 & $\mathrm{~W} /\left(\mathrm{m}^{2} \mathrm{~K}\right)$ \\
& $h_{2}$ & 15 & \\
& $h_{3}$ & 15 & \\
& $h_{4}$ & 14 & \\
Emissivity coefficients of different partitions & $\varepsilon_{1}$ & 0.02 & - \\
& $\varepsilon_{2}$ & 0.06 & \\
& $\varepsilon_{3}$ & 0.07 & \\
& $\varepsilon_{4}$ & 0.04 & \\
\hline
\end{tabular}

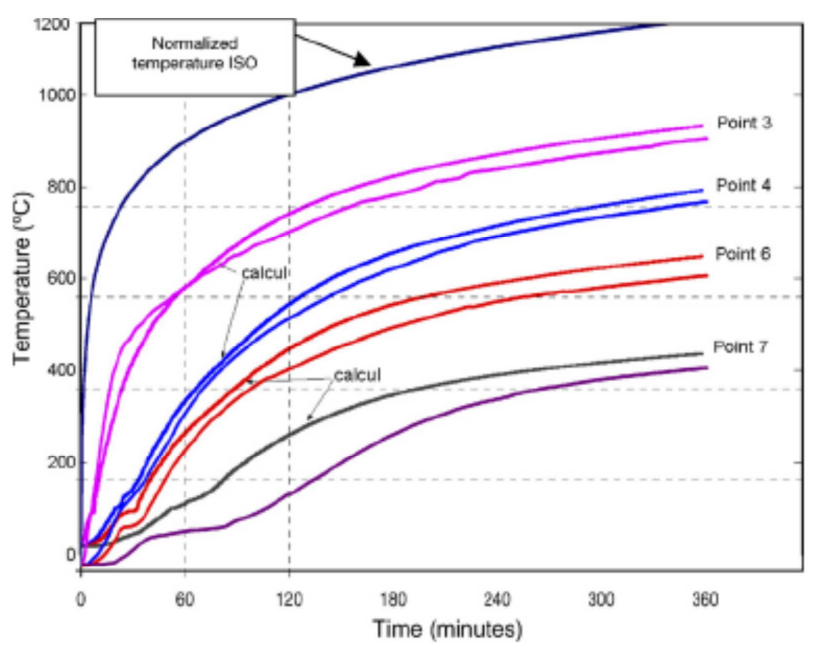

Fig. 10. Evolution of temperature through the wall as function of time. Comparison between experimental and theoretical predictions using thermal model. 
the boundary conditions for the three partitions are reported in Table 2.

Fig. 10 allows the comparison between the experimental results (obtained by temperature measurement during the heating of masonry wall) with the theoretical curves simulated using the formulation previously described (Eq. (30)).

It can be seen that the theoretical model estimates correctly the temperatures at nodes (4) and (6) as defined in Fig. 9 corresponding to measurement points (2) and (3) defined in Fig. 4b. It can be seen that the plateau of phase-change phenomenon at these points is also reproduced correctly. Concerning the node (7), (defined in Fig. 9 and corresponding to measurement point (4) in Fig. 4b), the model over-estimates by $35 \%$ the temperature, compared to that measured experimentally between 60 and $240 \mathrm{~min}$. This is probably due to the vapor re-condensation in the third partition which is not taken into account in this model. On the other hand, the model under-estimates by $4.5 \%$ the temperature in node (3) (defined in Fig. 9 and corresponding to measurement point (1) in Fig. 4 b) between 0 and $100 \mathrm{~min}$. This difference is probably due to the fact that the convection coefficient is supposed constant in the present model. In fact, the convection coefficient depends strongly on the temperature [10].

\section{Conclusion}

In the present study the experimental methodology used to characterize the thermo-mechanical behaviour of a masonry wall subjected to high temperature (until $1200^{\circ} \mathrm{C}$ ) has been shown. A vertical furnace has been used to apply this temperature with respect to the normalized ISO curve. The evolution of temperature inside the wall at different positions has been measured using thermocouples. During heating, the vertical and the lateral displacements of the wall were measured using LVDT transducers. The maximal values registered for the vertical and lateral displacements were almost 25 and $45 \mathrm{~mm}$, respectively. The experimental results highlighted the phase-change effect, which appears under a form of plateau on temperature and displacements curves. A thermal model has been developed to take into account the different phenomena observed during the experiments. This model is based on continuous heat transfer by convection, radiation and conduction through the different sections of the wall. An enthalpic method is used to incorporate the energy absorption by liquid water evaporation under a form of equivalent specific heat around the temperature of ebullition of interstitial water $\left(100^{\circ} \mathrm{C}\right)$. This model gave results that showed reasonable agreement with those obtained experimentally.

\section{Acknowledgements}

The authors would like to thank R. Eymard and G. Lauriat of Laboratory of Heat and Mass Transfer at University of Marne-La-Vallée for fruitful discussions on the subject.

\section{Appendix A}

\section{A.1. Energy balance for the second partition}

Similarly to the development done in the partition (1) (see Section 3.1.1), the energy balance for the partition (2) can be written:

$$
\left[\begin{array}{lll}
a_{11} & a_{12} & a_{13} \\
a_{21} & a_{22} & a_{23} \\
a_{31} & a_{32} & a_{33}
\end{array}\right] \times\left[\begin{array}{l}
\dot{T}_{4} \\
\dot{T}_{5} \\
\dot{T}_{6}
\end{array}\right]=\left[\begin{array}{l}
b_{4} \\
b_{5} \\
b_{6}
\end{array}\right]
$$

\section{where}

$$
\begin{aligned}
b_{4}= & {\left[h_{2}\left(T_{3}-T_{4}\right)+\sigma\left(T_{3}^{4}-T_{4}^{4}\right)\right.} \\
& \left.+\lambda\left(T_{4} c_{11}+T_{5} c_{12}+T_{6} c_{13}\right)\right] / \rho \cdot c_{4} \\
b_{5}= & {\left[\lambda\left(T_{4} c_{21}+T_{5} c_{22}+T_{6} c_{23}\right)\right.} \\
& \left.-\lambda\left(T_{4} c_{11}+T_{5} c_{12}+T_{6} c_{13}\right)\right] / \rho \cdot c_{5} \\
b_{5}= & {\left[-h_{3}\left(T_{6}-T_{7}\right)-\sigma\left(T_{6}^{4}-T_{7}^{4}\right)\right.} \\
& \left.-\lambda\left(T_{4} c_{21}+T_{5} c_{22}+T_{6} c_{23}\right)\right] / \rho \cdot c_{6}
\end{aligned}
$$

Eq. (26) can be written as follows:

$$
\left[\begin{array}{c}
\dot{T}_{4} \\
\dot{T}_{5} \\
\dot{T}_{6}
\end{array}\right]=\left[a_{i j}\right]^{-1}\left[\begin{array}{l}
b_{4} \\
b_{5} \\
b_{6}
\end{array}\right]
$$

\section{A.2. Energy balance for the third partition}

Similarly to the development done in the previous partitions, the energy balance for partition (3) can be written:

$$
\left[\begin{array}{lll}
a_{11} & a_{12} & a_{13} \\
a_{21} & a_{22} & a_{23} \\
a_{31} & a_{32} & a_{33}
\end{array}\right] \times\left[\begin{array}{l}
\dot{T}_{7} \\
\dot{T}_{8} \\
\dot{T}_{9}
\end{array}\right]=\left[\begin{array}{l}
b_{7} \\
b_{8} \\
b_{9}
\end{array}\right]
$$

where

$$
\begin{aligned}
b_{7}= & {\left[h_{3}\left(T_{6}-T_{7}\right)+\sigma\left(T_{6}^{4}-T_{7}^{4}\right)\right.} \\
& \left.+\lambda\left(T_{7} c_{11}+T_{8} c_{12}+T_{9} c_{13}\right)\right] / \rho \cdot c_{7} \\
b_{8}= & {\left[\lambda\left(T_{7} c_{21}+T_{8} c_{22}+T_{9} c_{23}\right)\right.} \\
& \left.-\lambda\left(T_{7} c_{11}+T_{8} c_{12}+T_{9} c_{13}\right)\right] / \rho \cdot c_{8} \\
b_{9}= & {\left[-h_{4}\left(T_{9}-T_{0}\right)-\sigma\left(T_{9}^{4}-T_{0}^{4}\right)\right.} \\
& \left.-\lambda\left(T_{7} c_{21}+T_{8} c_{22}+T_{9} c_{23}\right)\right] / \rho \cdot c_{9}
\end{aligned}
$$

Eq. (28) can be written as follows:

$$
\left[\begin{array}{c}
\dot{T}_{7} \\
\dot{T}_{8} \\
\dot{T}_{9}
\end{array}\right]=\left[a_{i j}\right]^{-1}\left[\begin{array}{l}
b_{7} \\
b_{8} \\
b_{9}
\end{array}\right]
$$

\section{References}

1] A.W. Hendry, F.M. Khalaf, Masonry Wall Construction, Spon Press, London, 2000.

2] CSTB, Arrêté du 3 août 1999 relatif à la résistance au feu des produits, écements de construction et d'ouvrages, chapitre $1^{\text {ef }}$ Journa Officiel de la république française, 11 septembre, 1999, p. 13638. 
[3] A.W. Hendry, Masonry walls: materials and construction, Construction and Building Materials (2001) 323-330.

4] F. Al Nahhas, Comportement Thermo-Mécanique des Murs en Maçonnerie de Blocs Creux en Beton sous l'Action d'un Feu Conventionnel, Thèse de doctorat de l'Université de Marne La Vallée, (2004).

[5] F. Al Nahhas, R. Ami Saada, P. Delmotte, G. Bonnet, Modélisation Thermo-hydrique des milieux poreux soumis à de hautes temperatures, XXIlèmes Rencontres Universitaires de Génie Civil (AUGC 04), 3-4 Juin, 8p., Marne La Vallée, France, 2004.

[6] Masonry 2007. Department of the Environment, London (1997).

[7] K. Thomas, Masonry walls, Butterworth-Heinemann, Oxford, 1996.

[8] A.M. Sowden, The Maintenance of Brick and Stone Masonry Structures, E. and F.N. Spon, London, 1990.

9] A.W. Hendry (Ed.), Reinforced and Pre-stressed Masonry Structures, Longman Scientific and Technical, Harlow, 1991

[10] Y. Bayazitoglu, M. Özisik Necati, Elements of Heat Transfer, McGraw-Hill, New York, 1988

[11] A. Nadjiai, M. O'Garra, F.A. Ali, D. Laverty, A numerical model for the behaviour of masonry under elevated temperature, Fire and Materials 27 (2003) 163-182.
[12] BS 5628, Code of Practice for Use of Masonry. Pt 1. Structural Use of Unreinforced Masonry, British Standards Institution, London, 1992.

[13] CP 121, Code of Practice for Walling. Pt 1: Brick and Block Masonry, British Standards Institution, London, 1973.

14] Eurocode No. 6, Design of Masonry Structures. Pt 10: Structura Fire Design, Commission of European Communities, Brussets, 1990.

[15] Building Regulations. Technical Booklet E. Fire Safety. Department of the Environment for Northern Ireland, June, 1994.

(16] N. Gnanakrishnan, R. Lawther, Some aspects of the fire performance of single leaf masonry construction. 2 International Symposium on Fire Engineering for Building Structures and Safety, Melbourne, 89/16, The Institution of Engineers, Australia, 1989, pp. $93-99$.

[17] F. Al Nahhas, R. Ami Saada, G. Bonnet, P. Delmotte, Heat and mas transfer coupling in porous media under high temperatures: modelisation and parametric study, Computer Methods in Applied Mechanics and Engineering, Submitted for publication.

18] C.R. Cruz, M. Gillen, Thermal expansion of Portland cement, mortar and concrete at high temperatures, Fire and Materiak 4 (1980). 